\title{
Somatic embryogenesis and vegetative cutting capacity are under distinct genetic control in Coffea canephora Pierre
}

\author{
Priyono $\cdot$ Bruno Florin $\cdot$ Michel Rigoreau $\cdot$ Jean-Paul Ducos $\cdot$ \\ Ucu Sumirat - Surip Mawardi - Charles Lambot • Pierre Broun • \\ Vincent Pétiard $\cdot$ Teguh Wahyudi $\cdot$ Dominique Crouzillat
}

Received: 16 October 2009/Revised: 26 January 2010/Accepted: 26 January 2010/Published online: 10 February 2010

(C) The Author(s) 2010. This article is published with open access at Springerlink.com

\begin{abstract}
The purpose of the study was to evaluate the possible genetic effect on vegetative propagation of Coffea canephora. Diversity for somatic embryogenesis (SE) ability was observed not only among two groups of C. canephora Pierre (Congolese and Guinean), but also within these different genetic groups. The results therefore showed that, under given experimental conditions, SE ability is depending on genotype. Furthermore the detection of quantitative trait loci (QTLs) controlling the SE and cutting abilities of $C$. canephora was performed on a large number of clones including accessions from a core collection, three parental clones and their segregating progenies. On the one hand we detected eight QTLs determining SE. Six positive QTLs for SE ability, whatever the criteria used to quantify this ability, were localized on one single chromosome region of the consensus genetic map. Two negative QTLs for SE ability (frequency of micro calli without somatic embryo) were detected on another linkage group. Deep analysis of the six QTLs detected for SE ability came to the conclusion that they can be assimilated to one single QTL explaining 8.6-12.2\% of the observed variation. On the other hand, two QTLs for average length of roots and length of the longest sprouts of cuttings were
\end{abstract}

Communicated by L. Jouanin.

Priyono $\cdot$ U. Sumirat $\cdot$ S. Mawardi $\cdot$ T. Wahyudi

Indonesian Coffee and Cocoa Research Institute,

Jl. PB. Sudirman 90, Jember 68118, Indonesia

B. Florin - M. Rigoreau - J.-P. Ducos - C. Lambot - P. Broun ·

V. Pétiard · D. Crouzillat $(\bowtie)$

Nestle R\&D Centre, 101 Avenue Gustave Eiffel,

37097 Tours Cedex 2, France

e-mail: dominique.crouzillat@rdto.nestle.com detected in two linkage groups. These QTLs detected for cutting ability are explaining $12-27 \%$ of the observed variation. These observations led to conclude that $\mathrm{SE}$ and cutting abilities of $C$. canephora Pierre appeared to be genetic dependent but through independent mechanisms.

Keywords Coffea canephora - Somatic embryogenesis . Cutting $\cdot$ Molecular marker $\cdot$ Quantitative trait loci
Abbreviations
QTL
SE
$\operatorname{FCM}(3 / 6)$
FSE(3/6)
ANEP(3/6)
Quantitative trait loci
ANERE(3/6)
Somatic embryogenesis embryogenic explant at third/sixth month of culture Frequency of micro calli without SE at third/sixth month of culture
FRC
ALS
ALR
Frequency of somatic embryogenesis at third/sixth month of culture
MLS
MLR Average number of embryos per Petri dish at third/sixth month of culture
Frequency of rooted cutting
Average length of sprout of cutting
Average length of root of cutting
Maximum length of sprout of cutting
Maximum length of root of cutting

\section{Introduction}

Coffee is one of the most important tropical commodities traded worldwide, with more than 6.5 million tons of green bean produced every year from about of 11 million 
hectares (Giridhar et al. 2004). Worldwide, at least 103 species and seven intraspecific taxa have been assigned to the genus Coffea (Rubiaceae) (Davis et al. 2006); however, commercial coffee production relies mainly on two species Coffea arabica and C. canephora. C. arabica accounts for more than $70 \%$ of the world's coffee production, having superior quality and flavour relative to $C$. canephora. Nevertheless, C. canephora is the main ingredient of soluble coffee, which is increasingly consumed throughout the world.

Coffee plantations cover 1.13 million ha in Indonesia, the fourth largest coffee producer in the world after Brazil, Colombia and Vietnam. Due to climatic and altitude considerations, more than $92 \%$ of Indonesian coffee production is based on C. canephora. Moreover, production and primary processing of coffee employs, approximately, 2 million families mainly smallholders. C. canephora is an outcrossing species. Hence, most plants are highly heterozygous and must be propagated as vegetative clones in order to maintain performance and quality characteristics.

One of the major problems of coffee production in Indonesia is the low productivity of the plantations. Most of the farmers commonly use seed-derived plantlets rather than vegetatively propagated high yielding ones. As a consequence, the release of superior clones of Robusta coffee to smallholding farmers is slow due to the technical and cost constraints of vegetative propagation. An efficient and rapid plant propagation technique, such as somatic embryogenesis (SE), would accelerate the distribution of superior clones to smallholding farmers, resulting in potentially large gains in productivity.

Coffee SE was first reported for C. canephora (var. Robusta) by Staritsky (1970) and C. arabica by Sondahl and Sharp (1977), who described the induction of embryoids from callus tissues. Subsequently, Hatanaka et al. (1991) obtained SE directly from leaf explants. The regeneration capability of Coffea spp by SE is extremely variable and depends on the species (Priyono 2004), the genotype (Michaux-Ferrière et al. 1989), the plant growth regulators (Yasuda et al. 1985), the cell density and frequency of medium renewal (Zamarripa et al. 1991), $\mathrm{CO}_{2}$ concentration (Uno et al. 2003) and dissolved $\mathrm{O}_{2}$ concentration (de Feria et al. 2003). It therefore depends on both genetic and environmental (culture conditions) factors. Conformity studies, conducted in the field on robusta clones have shown that SE techniques result in plants that are true to type (Ducos et al. 2003a). Recently, the use of SE has been applied for large scale production of C. canephora elite clones (Ducos et al. 2007). Today, SE is becoming the common method for the propagation of valuable genotypes in robusta coffee.
One of the main constraints of conventional coffee breeding is the difficulty in evaluating the relative influence of the genotype (i.e. genetic variance) versus the environment (i.e. environmental variance) on the phenotype. One of the obstacles to such studies is the relatively long generation time of coffee (3-4 years). Further exacerbating the problem is the reality that coffee, as a perennial crop, requires several years of growth before yield-related traits can be reliably measured in the field. The combination of these two factors explains the long time (about 20-25 years) required to select new coffee varieties or clones. In this context, the utilization of molecular markers associated with quantitative trait loci (QTLs) could increase the breeding efficiency thanks to an increase of selection accuracy. The accumulation of QTLs determining plant vegetative propagation process with other QTLs for traits of interest, such as yield might lead to the more rapid creation of new elite clones.

Using different types of mapping populations, such as recombinant inbred lines, $\mathrm{F}_{2}$ or double haploids, it has been possible to detect QTLs for various tissue culture responses on several crops. For example, QTLs controlling callusing ability have been detected in rice (Lannes et al. 2004). In addition, QTLs controlling embryogenic callus ability have been reported in maize (Krakowsky et al. 2006) and sunflower (Huang et al. 2007). QTLs controlling organogenesis ability have been detected in a number of species including tomato (Koornneef et al. 1993), poplar (Han et al. 1994), rice (Taguchi-Shiobara et al. 1997), barley (Mano and Komatsuda 2002), Arabidopsis (Schiantarelli et al. 2001; Lall et al. 2004), broccoli (Holme et al. 2004). Finally, QTLs controlling the SE ability have been reported for sunflower (Flores-Berios et al. 2000) and rye (Bolibok et al. 2007).

Quantitative trait loci have also been reported for the ability of plants to be developed from vegetative cutting. In Eucalyptus 20 QTLs were reported: 4 QTLs controlling rooting ability, 6 for sprout ability, and 10 for fresh weight of shoots (Grattapaglia et al. 1995). In poplar, 4 QTLs were determined to control bud set and 6 for bud flush (Frewen et al. 2000). A recent study has reported 6 QTLs controlling rooting ability of Pendunculate oak cuttings (Scotti-Saintagne et al. 2005). However, until now, there has been no reporting the genetic basis and QTL control of either SE or vegetative cuttings in Coffea spp.

The goals of this study were (i) to determine the extent to which SE technique is a reproducible technique (ii) to evaluate SE and cutting ability of a large population of $C$. canephora including parental clones and their segregating progenies, and (iii) to use the variability observed for SE and cutting ability to search the possible QTLs 
linked to vegetative multiplication ability by these two techniques.

\section{Materials and methods}

Plant material

Coffea canephora were from three different origins (i) a set of seven accessions from the Nestlé Coffee Core Collection (Pétiard et al. 2004), which represents two groups of C. canephora, i.e. Congolese group (FRT23, FRT56, FRT31 and FRT80), Guinean group (FRT09 and FRT16) (ii) a set of three elite parental clones from Indonesian Coffee and Cocoa Research Institute (ICCRI), i.e. BP409 and BP961 (Congolese group), Q121 (an hybrid between Guinean and Congolese), (iii) a set of two controlled hybrid populations CPA $($ BP961 × Q121) and CPB (BP409 × Q121), comprising of 78 and 93 individuals respectively.

The three parental Indonesian clones and the two segregating populations were propagated by cuttings at ICCRI (Indonesia). Then one set of them was kept in the experimental fields of ICCRI and another one was transferred to France and maintained in the greenhouse of Nestle R\&D Centre Tours (France).

\section{Methods}

Somatic embryogenesis procedure

Leaf explants were harvested from 2 to 3 paired positions from the top of greenhouse-grown plants. For decontamination, the leaves were washed with sterile water and then immersed first in $70 \%$ ethanol solution for $30 \mathrm{~s}$ and then in a $4 \% \mathrm{NaOCl}$ solution with a few drops of Tween 20 for $30 \mathrm{~min}$. Finally the leaves were rinsed three times with sterile water. Sterilized leaves were cut into small pieces $(10 \times 10 \mathrm{~mm})$ and placed in a Petri dish containing $40 \mathrm{ml}$ of semi solid SE medium.

The SE protocol used in this study was developed by Priyono (2004). The composition of SE medium was half concentration of MS basal medium (Murashige and Skoog 1962), with also half concentration Gamborg's vitamin medium (Gamborg et al. 1976). It was supplemented with $1 \mathrm{mg} / \mathrm{l} \mathrm{L}$-cysteine, $10 \mathrm{mg} / \mathrm{l} \mathrm{Ca-pantothenate,} 100 \mathrm{mg} / \mathrm{l}$ casein hydrolysate, $50 \mathrm{mg} / \mathrm{l}$ adenine sulphate, $5 \mathrm{mg} / \mathrm{l}$ kinetin, and $40 \mathrm{~g} / \mathrm{l}$ sucrose. Finally, $3 \mathrm{~g} / \mathrm{l}$ of Gelrite were added as a gelling agent.

For each genotype, ten Petri dishes containing 15 explants per dish were inoculated. For SE induction the Petri dishes were placed for 6 months in a culture room at $25^{\circ} \mathrm{C}$ under cool-white fluorescent lamps, providing approximately $30 \mu \mathrm{mol}$ photon $/ \mathrm{m}^{2}$ over a $16 \mathrm{~h}$ photoperiod. Except for the comparison of SE performance between two laboratories all SE experiments were carried out at Nestlé R\&D Tours, France. For the comparison between the two laboratories we used the same genotypes and experimental conditions were as much similar as possible.

\section{Cutting procedure}

The cutting technique used was based on a single node without any hormonal treatment or fertilizer. All cuttings were planted individually and covered by plastic tunnel under artificial shading to provide approximately $60 \%$ of sun light. About 95\% RH was maintained by applying irrigation every 3 days during the 3 months of the trial. For each genotype, 30 single nodes were used. This experiment was carried out at the ICCRI experimental station (Indonesia).

Evaluation of somatic embryogenesis and cutting ability

1. Evaluating the SE ability of different genetic stocks. The seven accessions from the Nestlé Coffee Core Collection along with the three elite parental clones from ICCRI were evaluated for SE ability in a completely randomized design with ten replications (Petri dishes) of 15 explants per replication (10 genotypes $\times 10$ Petri dish $\times 15$ leaf pieces). Individuals from the two segregating populations (CPA and CPB) were evaluated in a similar manner, also with ten replications of each genotype.

2. Evaluating the effects of three factors on SE ability.

a) Donor plant: Due to possible physiological differences the donor plant of a given genotype can potentially exert a significant influence on $\mathrm{SE}$ ability. To test for this an experiment was set up in factorial completely randomized design, with 10 replications (Petri dish) of 15 explants per replication. The first factor was the mother plant (two cuttings of the considered genotype) and the second factor was the genotype (3 individuals from both CPA and CPB): 6 genotypes $\times 2$ plants $\times 10$ Petri dishes $\times 15$ leaf pieces.

b) Timing of explant harvest: Also due to possible physiological differences depending on the timing of explant harvest (season) explants were harvested over 1 year period. The experiment was set up in factorial completely randomized design in 10 replications with 15 explants per replication. The first factor was harvesting time which consist 
of four culture periods (March, June, September, and December) and second factor was the genotype, which consists of 9 genotypes ( 3 individuals from both CPA and CPB plus the three parents): 9 genotypes $\times 4$ harvesting times $\times 10$ Petri dishes $\times 15$ leaf pieces.

c) Laboratory location: The experiment was set up in factorial completely randomized design, in 10 replications with 15 explants per replication. The first factor was laboratory location (two laboratories: France and Indonesia) and second factor was progeny, representing the extreme values for SE ability previously observed in France (26 individuals of CPA and 21 individuals of CPB): 47 genotypes $\times 2$ laboratories $\times 10$ Petri dishes $\times$ 15 leaf pieces.

3. Evaluating SE ability in segregating populations for QTL mapping. The CPA and CPB segregating populations (76 and 86 individuals respectively) were evaluated for SE ability with the same experimental design as described above including 10 replications of 15 explants.

4. Evaluating the ability for vegetative cutting in segregating population for QTL mapping. Experiment was set up for CPA and CPB with the number of 75 and 89 descendents, respectively with 3 replications of 10 single orthotropic cuttings planted in current nursery conditions in Indonesia.

\section{Data observation and recording}

For SE technique, three criteria were observed and recorded after 3 and 6 months of culture leading to the calculation of six variables as follows: the number of explants with micro calli without embryo named FMC (frequency of micro calli), the number of explants with somatic embryo(s) named FSE (frequency of embryogenic explant), and the average number of embryos per embryogenic explant named ANERE (yield per embryogenic explant). The average number of embryos per Petri dish (ANEP) was calculated as FSE $\times$ ANERE. Ultimately, SE ability was expressed as the percentage of embryogenic explants and the average number of embryos per embryogenic explant (see Table 1).

To characterize cutting ability, five criteria were observed and recorded 3 months after the cutting were made, and expressed as follows: the number of cuttings with both sprouts and roots named FRC (frequency of successful cuttings), the average length of sprouts named ALS, length of the longest sprout named MLS, and finally the average length of the roots named ALR and the length of the longest root named MLR.

\section{Statistical analyses}

The statistical analyses were done according to Pearson for the correlation study. The ANOVA (1 or 2 factors) followed by the Tukey-Kramer comparison test was used for the evaluation of SE ability. Heritability is the relative amount of variation caused by genetic variability. ANOVA analysis was performed by Statbox6 software (version 6.5) to calculate the variance for estimating the $h$ broad sense of heritability of each trait, where $h$ is defined as (Lee 2009):

Heritability $(h)=\frac{\text { Genetic variation among individuals }\left(V_{\mathrm{g}}\right)}{\text { Genetic variation }\left(V_{\mathrm{g}}\right)+\text { Environmental }}$

Genetic mapping and quantitative trait loci analysis

DNA of 78 and 93 individuals from controlled hybrid populations, BP961 $\times$ Q121 $(\mathrm{CPA})$ and BP409 $\times$ Q121 (CPB), were extracted using the DNeasy Plant Maxi Kit (http://www.qiagen.com). Selected microsatellite markers (SSRs), based on the covering of the 11 linkage groups, from both ESTs and genomic origins (Lin et al. 2005; Poncet et al. 2007) were used to construct genetic maps for each population. Genetic maps were constructed by using JoinMap $^{\circledR}$ software (van Ooijen 2006) with Kosambi's mapping function (Kosambi 1944). First, a genetic map was constructed for each population. The CPA and CPB populations contained 199 and 280 loci respectively.

Table 1 Criteria description for the evaluation of somatic embryogenesis ability of Coffea canephora Pierre

\begin{tabular}{llll}
\hline No. & Criteria & Name & Calculation \\
\hline $\begin{array}{l}\text { 1. } \\
\begin{array}{l}\text { Frequency of micro calli without somatic } \\
\text { embryogenesis }\end{array}\end{array}$ & FMC & Number of explants showing micro calli without somatic embryo expression \\
2. & $\begin{array}{l}\text { Frequency of embryogenic explant } \\
\text { 3. }\end{array}$ & $\begin{array}{l}\text { FSE } \\
\text { 4. }\end{array}$ & $\begin{array}{c}\text { Number of explants which produces at least one embryo per 15 inoculated } \\
\text { explants }\end{array}$ \\
\hline
\end{tabular}


Since the Q121 parent was shared by both segregating populations, it was also possible to construct a backcross genetic map (BCQ121) comprising the 171 individuals of CPA and CPB populations. This map contained 133 markers.

Finally, a consensus genetic map from CPA and CPB populations, consisting of $350 \mathrm{loci}$, was constructed in order to plot all QTLs detected on the same framework.

The MapQTL5 ${ }^{\circledR}$ software (van Ooijen 2004) was used for QTLs detection on the three genetic maps. In a first step, the non-parametric Kruskal-Wallis (KW) test was applied to detect individually significant association $(\alpha=0.05)$ between markers and traits. The significant $\mathrm{K}$ threshold of 12.9, 16 and 18.6 were used with $d f=1$ for two genotype classes (backcross type abxaa or aaxab), $d f=2$ for three genotype classes $\left(\mathrm{F}_{2}\right.$ segregation type: abxab) and $d f=3$ for four genotype segregating classes (abxac or abxcd), respectively.

In a second step, interval mapping (IM) analysis was used to detect QTL. Log of odds (LOD) thresholds for genome wide were experimentally determined for a given trait using the permutation test of MAPQTL with 1,000 iterations. Then threshold LOD values of 4 and 3 for cross pollinated and backcross segregations respectively, have been defined and used to declare the presence of a QTL. A QTL is validated when both LOD and K tests are significant. The genetic linkage groups carrying QTLs were represented using MapChart software (van Ooijen 2006).

\section{Results}

Genetic variation for somatic embryogenesis ability

In this study, SE was induced under cytokinin stress due to the addition of kinetin in the culture medium. The reactivity of leaf explants appeared rapidly. After 1 month of culture, microscopic examinations revealed that some leaf explants had produced micro calli or globular projection at the cut end of the leaf. After a longer culture time, all embryos stages from heart, torpedo to cotyledonary shaped embryos could be observed on embryogenic explants (Fig. 1c) whereas other explants showed only micro calli without embryo expression (Fig. 1b). After 6 months, single bipolar somatic embryos were easily isolated on the primary embryos showing the existence of an additional phenomenon of secondary embryos production (Fig. 1d). The last stage of somatic embryo development was characterized by the presence of cotyledons, apical and radical meristems and a morphological aspect similar to seed embryos. At the end of the culture period (6 months), some explants have no response at all (Fig. 1a).

For practical reasons this study required to use different plants at different time for each genotype. The reproducibility of SE ability according to the mother plant, time of explant harvest, and environment (laboratories) had therefore to be controlled. No significant difference $(\alpha=0.01)$ between cuttings from a same clone, time of explant
Fig. 1 Coffea canephora somatic embryogenesis induction. 1-1 Leaf explant with any in vitro response, 1-2 explant produced micro calli without somatic embryogenesis, 1-3 explant produced primary somatic embryos, and 1-4 secondary somatic embryogenesis formed from primary embryos

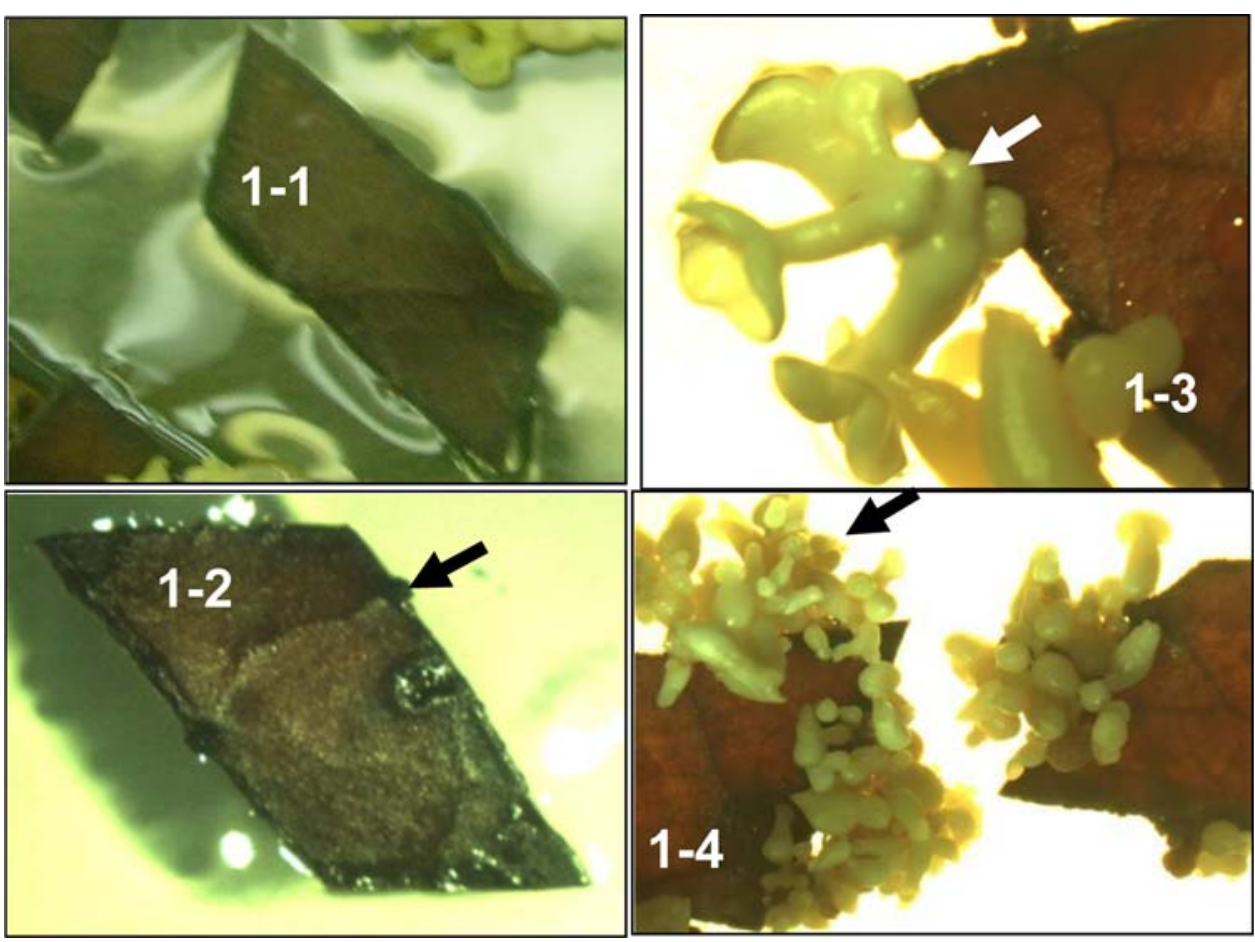


harvest over 1 year, and laboratories (Indonesia and France) was detected (results not shown). Based on these observations we infer that SE ability is not significantly affected by these three factors which could have been at the origin of artefact limiting further detection of QTLs.

The SE ability has then been compared for 10 genotypes representative of the genetic diversity of $C$. canephora. Based on statistical analysis, significant differences were observed between these genotypes for all traits (Table 2). The somatic embryogenesis frequency (FSE) after 6 months was $0-1 \%$ for the two Guinean clones FRT09 and FRT16 as well as for two Congolese clones (FRT51 and FRT56). However, in the same experiment SE frequency reaches $71 \%$ for another Congolese clone (FRT23) and 55-57\% for the two other clones (FRT80 and FRT31). These results demonstrate SE variability not only among the two groups of $C$. canephora (Congolese and Guinean), but also within a given genetic group (Congolese). Moreover, the three ICCRI clones (BP409, BP961 and Q121) used as parents for controlled crosses, showed significant differences for SE.

Somatic embryogenesis ability was evaluated after 3 and 6 months of culture on induction medium. As reported in Table 3, based on 16 genotypes ( 10 genotypes for diversity of SE ability and 3 genotypes selected randomly from each hybrid populations CPA and CPB) a significant difference between 3 and 6 months of culture was observed for all criteria, except for the frequency of microcalli without embryo (FMC). However, a significant difference in the interaction between genotype and culture duration for FMC was also observed. In fact, between 3 and 6 months (Table 3), FMC increases for genotypes characterized by a low FSE ability (for example FRT16) and FMC decreases for genotypes characterized by a high FSE ability (for example BP409).

Table 2 Somatic embryogenesis ability of 10 genotypes from three genetic groups of Coffea canephora Pierre

\begin{tabular}{|c|c|c|c|c|c|c|c|c|}
\hline \multirow[t]{3}{*}{ Genotype $^{\mathrm{A}}$} & \multicolumn{8}{|c|}{ SE ability } \\
\hline & \multicolumn{4}{|c|}{3 months of culture } & \multicolumn{4}{|c|}{6 months of culture } \\
\hline & FMC3 & FSE3 & ANERE3 & ANEP3 & FMC6 & FSE6 & ANERE6 & ANEP6 \\
\hline FRT80 (Cl) & $10 \mathrm{ab}$ & $41 \mathrm{~b}$ & $17 \mathrm{c}$ & $190 \mathrm{~b}$ & $6 \mathrm{a}$ & $55 \mathrm{bc}$ & $25 \mathrm{c}$ & $291 \mathrm{c}$ \\
\hline FRT31(Cl) & $22 \mathrm{ab}$ & $27 \mathrm{~b}$ & $5 \mathrm{ab}$ & $29 \mathrm{a}$ & $18 \mathrm{ab}$ & $57 \mathrm{bcd}$ & $22 \mathrm{bc}$ & $215 \mathrm{bc}$ \\
\hline FRT16 (G) & $65 \mathrm{c}$ & $0 \mathrm{a}$ & $0 \mathrm{a}$ & $0 \mathrm{a}$ & $82 \mathrm{c}$ & $0 \mathrm{a}$ & $0 \mathrm{a}$ & $0 \mathrm{a}$ \\
\hline FRT09 (G) & $17 \mathrm{ab}$ & $0 \mathrm{a}$ & $0 \mathrm{a}$ & $0 \mathrm{a}$ & $18 \mathrm{ab}$ & $0 \mathrm{a}$ & $0 \mathrm{a}$ & $0 \mathrm{a}$ \\
\hline FRT23 (Cg) & $67 \mathrm{c}$ & $33 \mathrm{~b}$ & $2 a b$ & $22 \mathrm{a}$ & $29 \mathrm{ab}$ & $71 \mathrm{~cd}$ & $13 \mathrm{abc}$ & 186 bc \\
\hline FRT51 (Cg) & $0 \mathrm{a}$ & $1 \mathrm{a}$ & $0 \mathrm{a}$ & $1 \mathrm{a}$ & $0 \mathrm{a}$ & $1 \mathrm{a}$ & $0 \mathrm{a}$ & $1 \mathrm{a}$ \\
\hline FRT $56(\mathrm{Cg})$ & $21 \mathrm{ab}$ & $0 \mathrm{a}$ & $0 \mathrm{a}$ & $0 \mathrm{a}$ & $37 \mathrm{~b}$ & $1 \mathrm{a}$ & $0 \mathrm{a}$ & $0 \mathrm{a}$ \\
\hline BP409 (Cg)* & $27 \mathrm{ab}$ & $67 \mathrm{c}$ & $12 \mathrm{bc}$ & $148 \mathrm{~b}$ & $18 \mathrm{ab}$ & $79 \mathrm{~d}$ & $21 \mathrm{bc}$ & $275 \mathrm{c}$ \\
\hline BP961 (Cg)* & $11 \mathrm{ab}$ & $31 \mathrm{~b}$ & $4 \mathrm{ab}$ & $57 \mathrm{a}$ & $9 \mathrm{ab}$ & $35 \mathrm{~b}$ & $6 \mathrm{ab}$ & $80 \mathrm{ab}$ \\
\hline Q121 $(\mathrm{Cg} \times \mathrm{G})^{*}$ & $31 \mathrm{~b}$ & $3 \mathrm{a}$ & $0.1 \mathrm{a}$ & $1 \mathrm{a}$ & $31 \mathrm{ab}$ & $3 \mathrm{a}$ & $0.3 \mathrm{a}$ & $2 \mathrm{a}$ \\
\hline
\end{tabular}

A $C l$ Conillon, $G$ Guinean, $C g$ Congolese

* Clone used as parental of CPA and CPB hybrid populations. Results in the same column followed by the same letters are not significantly different for $\alpha=0.05$ as analysis by repeated measures ANOVA, followed by Tukey-Kramer multiple-comparison test

Table 3 Variance analysis on effect of induction duration for the SE ability of 16 Coffea canephora genotypes

\begin{tabular}{|c|c|c|c|c|c|}
\hline & \multirow[t]{2}{*}{ Source } & \multicolumn{4}{|l|}{ SE ability } \\
\hline & & FMC & FSE & ANERE3 & ANEP \\
\hline \multirow[t]{3}{*}{$F$-ratio } & A: genotype ${ }^{a}$ & 17.00 & 14.51 & 11.14 & 8.42 \\
\hline & $\mathrm{B}$ : duration of culture ${ }^{\mathrm{b}}$ & 0.46 & 19.50 & 25.20 & 19.95 \\
\hline & AB: interaction & 2.32 & 1.28 & 2.26 & 1.64 \\
\hline \multirow[t]{3}{*}{ Prob. level } & A: genotype & $<0.00001$ & $<0.00001$ & $<0.00001$ & $<0.00001$ \\
\hline & B: duration of culture & 0.50 & $<0.00001$ & $<0.00001$ & $<0.00001$ \\
\hline & $\mathrm{AB}$ : interaction & 0.00410 & 0.21600 & 0.00513 & 0.06431 \\
\hline
\end{tabular}


This observation supports the idea that a genotype with propensity for callogenesis may not be inclined to form embryos without significant modifications of the environment.

Somatic embryogenesis ability of the two hybrid populations

A total of 25.050 leaf explants were cultured for the evaluation of SE ability of two hybrid populations (CPA and $\mathrm{CPB}$ ). The results after 3 and 6 months of culture are summarized in Table 4. In CPA, the parental clone BP961 showed higher SE ability than Q121 for all criteria, except for the frequency of micro callus. A similar result is observed for the parental clone BP409 compare to Q 121 from CPB.

A large range of variation of SE ability was observed after 3 and 6 months of culture within the two hybrid populations. After 6 months the frequency of micro calli (FMC) varies from 0 to $72 \%$ with an average of $18.8 \%$ for CPA and from 0 to $74 \%$ with an average of $17 \%$ for CPB. The frequency of SE (FSE) varies from 0 to $88 \%$ with an average of $23.4 \%$ for CPA and from 0 to $100 \%$ with an average of $40 \%$ for CPB. A large variation is also observed for the number of embryo per embryogenic explant (ANERE). It varies from 1.3 to 28 embryos with an average of 7.7 embryos for CPA and from 1 to 55 embryos with an average of 28 embryos for CPB (see Fig. 2).
In addition $13(17 \%)$ and 7 (8\%) individuals of CPA and CPB respectively, did not expressed any embryogenic capacity. The variability of SE ability is shown in Fig. 3 reporting the distribution of SE frequency for the two hybrid populations. Among the three parental clones, BP409 shows the highest potential and Q121 the lowest one. Furthermore, the $\mathrm{h}$ values expressing heritability of different SE ability parameters vary from 0.76 to 0.90 for $\mathrm{CPA}$ and from 0.51 to 0.98 for $\mathrm{CPB}$, which show a high heritability (Table 4).

Cutting ability of the two hybrid populations

A total amount of 5.010 node cuttings were planted for the evaluation of cutting ability of the two hybrid populations (CPA and $\mathrm{CPB}$ ). After 3 weeks single nodes started to sprout. After 3 months cutting, with and without roots, could be observed (Fig. 3) but no rooted ones without sprout. In this study, the induction of both sprout and root did not require growth regulator.

The cutting ability parameters recorded after 3 months are reported in Table 5. In CPA the parent Q121 shows either similar or lower ability than the other parent BP961 for all criteria except for the average and maximum length of roots. On the contrary, in CPB, this clone Q121 shows higher ability than the other parent BP409 for all traits, except the frequency of rooted cuttings. Thus Q121 looks less capable to form rooted cuttings than the two other

Table 4 Evaluation of somatic embryogenesis ability in CPA (BP961 × Q121) and CPB (BP409 × Q121) of Coffea canephora Pierre

\begin{tabular}{|c|c|c|c|c|c|c|c|c|}
\hline \multirow[t]{3}{*}{ Descriptions } & \multicolumn{8}{|c|}{ SE ability ${ }^{B}$} \\
\hline & \multicolumn{4}{|c|}{3 months of culture } & \multicolumn{4}{|c|}{6 months of culture } \\
\hline & FMC3 & FSE3 & ANERE3 & ANEP3 & FMC6 & FSE6 & ANERE6 & ANEP6 \\
\hline $\mathrm{BP} 409^{\mathrm{A}}$ & $27 \mathrm{a}$ & $67 \mathrm{~b}$ & $12 \mathrm{~b}$ & $148 \mathrm{~b}$ & $18 a b$ & $79 \mathrm{c}$ & $21 \mathrm{~b}$ & $275 \mathrm{~b}$ \\
\hline BP961 ${ }^{\mathrm{A}}$ & $11 \mathrm{a}$ & $31 \mathrm{a}$ & $4 \mathrm{a}$ & $57 \mathrm{a}$ & $9 \mathrm{a}$ & $35 \mathrm{~b}$ & $6 \mathrm{a}$ & $80 \mathrm{a}$ \\
\hline $\mathrm{Q} 121^{\mathrm{A}}$ & $31 \mathrm{a}$ & $3 \mathrm{a}$ & $0.1 \mathrm{a}$ & $1 \mathrm{a}$ & $31 \mathrm{~b}$ & $3 \mathrm{a}$ & $0.3 \mathrm{a}$ & $2 \mathrm{a}$ \\
\hline Min value of pop A & 0 & 0 & 1.0 & 0 & 0 & 0 & 1.3 & 0 \\
\hline Min value of pop B & 0 & 0 & 1.0 & 0 & 0 & 0 & 1.0 & 0 \\
\hline Max value of pop A & 83 & 76 & 15 & 142 & 72 & 88 & 28 & 322 \\
\hline Max value of pop B & 79 & 97 & 37 & 403 & 74 & 100 & 55 & 667 \\
\hline Avr value of pop A & 24.6 & 14.9 & 3.0 & 9.4 & 18.8 & 23.4 & 7.7 & 35.3 \\
\hline Avr value of pop B & 21.3 & 29.5 & 7.7 & 46.4 & 17.0 & 40.0 & 27.8 & 138.2 \\
\hline Heritability in pop A & 0.80 & 0.77 & 0.78 & 0.76 & 0.78 & 0.86 & 0.84 & 0.90 \\
\hline Heritability in pop B & 0.92 & 0.54 & 0.49 & 0.51 & 0.98 & 0.57 & 0.54 & 0.56 \\
\hline
\end{tabular}

A Parental clones used to obtain hybrid population, results in the same column of three parental clones followed by the same letters are not significantly different for $\alpha=0.05$ as analysis by one way ANOVA, followed by Tukey-Kramer multiple-comparison test

B FMC3 Frequency of micro calli at 3 month after culture, FSE3 frequency of somatic embryogenesis at 3 month after culture, ANERE3 average number of embryos per reactive explant at 3 month after culture, ANEP3 average number of embryos per Petri dish at 3 month after culture, FMC6 frequency of micro calli at 6 month after culture, FSE6 frequency of somatic embryogenesis at 6 month after culture, ANERE6 average number of embryos per reactive explant at 6 month after culture and ANEP6 average number of embryos per Petri dish at 6 month after culture 
Fig. 2 Cutting responses of Coffea canephora. 2-1 Sprouted cutting, 2-2 rooted cutting
Fig. 3 Frequency distribution of the somatic embryogenesis rate, at sixth month of culture (FSE6), on the two hybrid populations (CPA and $\mathrm{CPB})$ of Coffea canephora. The value of FSE6 for the BP409, BP961 and Q121 clones were 79, 35 and $3 \%$, respectively
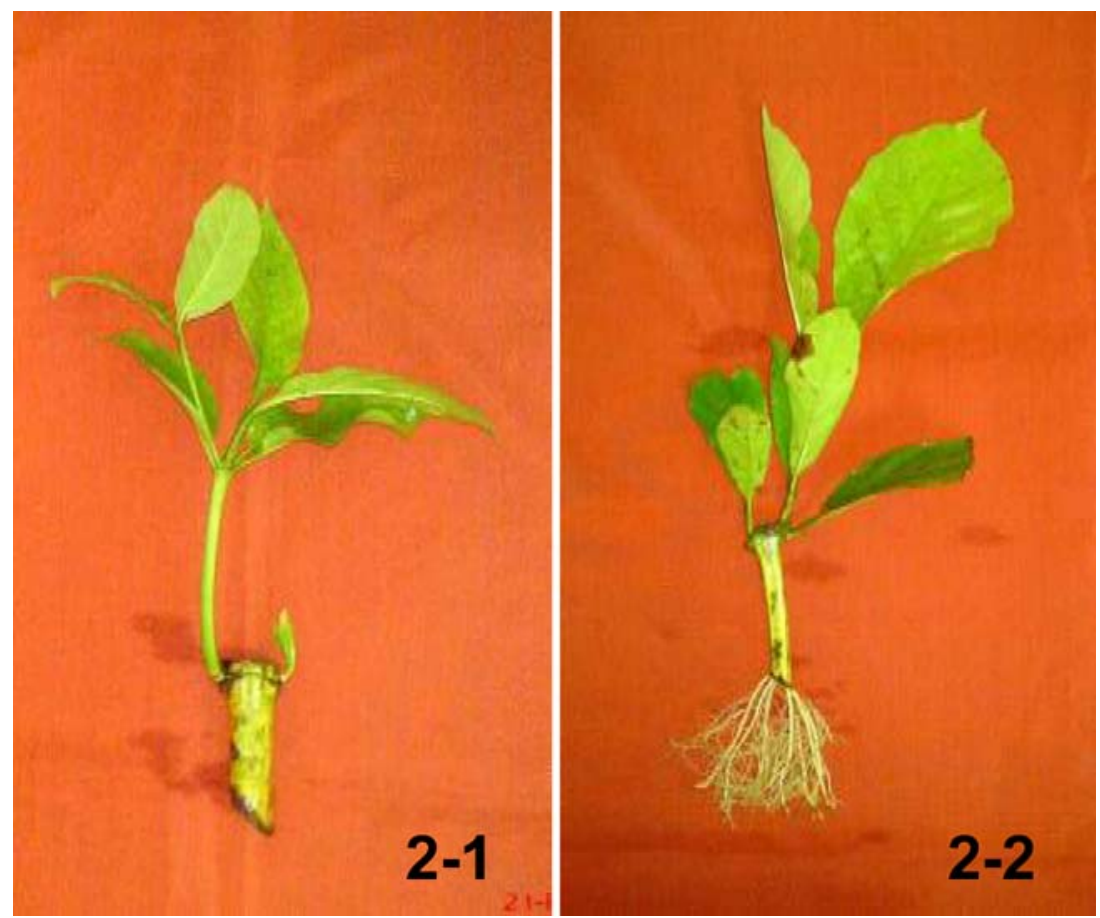

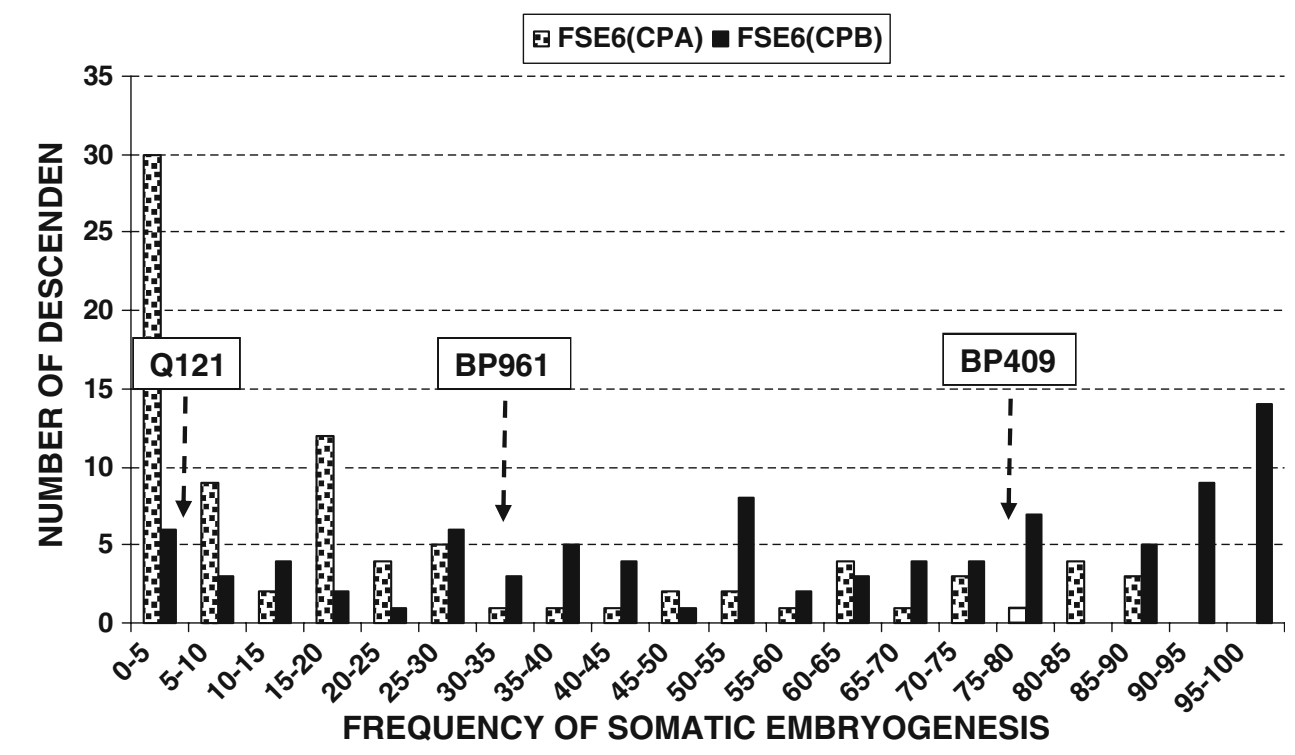

parents. However, the few developed ones are more vigorous than those of BP409.

The frequency of rooted cuttings in CPA population varies from 12 to $96 \%$ with an average of $62.2 \%$, whereas in the $\mathrm{CPB}$, it varies from 8 to $96 \%$ with an average of $48.3 \%$. The number of root per cutting varies from 2 to 7 roots with an average of 3.3 roots for CPA and from 1 to 6 roots with an average of 2.7 roots for CPB. The root length varies from 4 to $10 \mathrm{~cm}$ with an average of $7.2 \mathrm{~cm}$ for CPA and from 2 to $10 \mathrm{~cm}$ with an average of $6.4 \mathrm{~cm}$ for $\mathrm{CPB}$ (Table 5). It is interesting to note that all genotypes have some ability to produce roots but no true tap root has been developed from these orthotropic cuttings

The distribution of the two hybrid populations according to the frequency of rooted cuttings is shown in Fig. 4. The heritability test for cutting ability criteria also shows an important variation since as examples the $h$ value varies from 0.09 (ALR) to 0.72 (MLS) for CPA. 
Table 5 Evaluation of cutting ability in CPA (BP961 X Q121) and CPB (BP409 X Q121) of Coffea canephora Pierre at 3 months of cutting process

\begin{tabular}{llllll}
\hline Descriptions & \multicolumn{5}{l}{ Cutting ability } \\
\cline { 2 - 6 } & FRC & ALR & ALS & MLR & MLS \\
\hline BP409 $^{\text {A }}$ & $58 \mathrm{a}$ & $3 \mathrm{a}$ & $2 \mathrm{a}$ & $8 \mathrm{a}$ & $5 \mathrm{a}$ \\
BP961 $^{\mathrm{A}}$ & $75 \mathrm{a}$ & $6 \mathrm{ab}$ & $5 \mathrm{~b}$ & $10 \mathrm{a}$ & $8 \mathrm{a}$ \\
Q121 $^{\mathrm{A}}$ & $44 \mathrm{a}$ & $10 \mathrm{~b}$ & $4 \mathrm{ab}$ & $16 \mathrm{~b}$ & $9 \mathrm{a}$ \\
Min value of pop A & 12 & 4 & 3 & 8 & 6 \\
Min value of pop B & 8 & 2 & 4 & 3 & 9 \\
Max value of pop A & 96 & 10 & 11 & 19 & 22 \\
Max value of pop B & 96 & 10 & 12 & 20 & 26 \\
Avr value of pop A & 62.2 & 7.2 & 7.1 & 12.5 & 14.3 \\
Avr value of pop B & 48.3 & 6.4 & 6.8 & 11.4 & 14.0 \\
Heritability in pop A & 0.28 & 0.09 & 0.65 & 0.23 & 0.72 \\
Heritability in pop B & 0.44 & 0.28 & 0.13 & 0.43 & 0.13 \\
\hline
\end{tabular}

A Parental clones used to obtain hybrid population, results in the same column of three parental clones followed by the same letters are not significantly different for $\alpha=0.05$ as analysis by one way ANOVA, followed by Tukey-Kramer multiple-comparison test

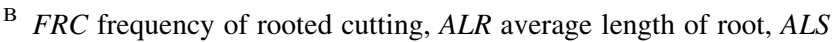
average length of sprout, $M L R$ maximum length of root, and $M L S$ maximum length of sprout

Correlation between the somatic embryogenesis and cutting

Based on the association of eight criteria for SE ability and five for cutting ability no significant correlation was observed except for ANERE with FRC at 6 months $(r=-0.26, p=0.01)$. This observation leads to suppose that these two phenomena are independent mechanisms.

\section{Quantitative trait loci detection}

\section{Coffee genetic mapping}

199 markers on 78 genotypes were used for the construction of the CPA map representing the 11 linkage groups of C. canephora. This CPA map covers $1,165 \mathrm{cM}$ with an average locus density of $6.2 \mathrm{cM}$. Among the 199 loci, 100 $(50 \%), 45(23 \%)$, and 54 (27\%) showed, respectively, $\mathrm{F}_{2}$, backcross to BP961, and backcross to Q121, segregation type.

280 markers on 93 genotypes were used for the construction of the CPB map. This CPB map covers 1,320 cM with an average locus density of $4.9 \mathrm{cM}$. Among the 280 loci, 119 (43\%), 99 (35\%), and 62 (22\%) have, respectively, $\mathrm{F}_{2}$, backcross to BP409 and backcross to Q121, segregation type.

133 markers segregating for Q121, in 171 plants from both CPA and CPB, were combined to construct the BC Q121 map. This map covers $947 \mathrm{cM}$ with an average locus density of $8.6 \mathrm{cM}$.

This approach allowed to detect QTLs on these three maps and to transfer them on a consensus genetic map allowing to compare their locations. This map, including 350 markers, covers $1,315 \mathrm{cM}$ with an average locus density of $3.9 \mathrm{cM}$.

\section{QTLs determination}

No QTL was detected for SE ability on the CPA and CPB populations characterized by a low number of individuals (78 and 93, respectively). One hypothesis is that the low number of segregating plants does not permit the detection
Fig. 4 Frequency distribution of rooted cutting at 3 month of observation on the two hybrid populations (CPA and $\mathrm{CPB}$ ) of Coffea canephora Pierre. The value of FRC of the BP409, BP961 and Q121 clone were 58, 75 , and $44 \%$, respectively

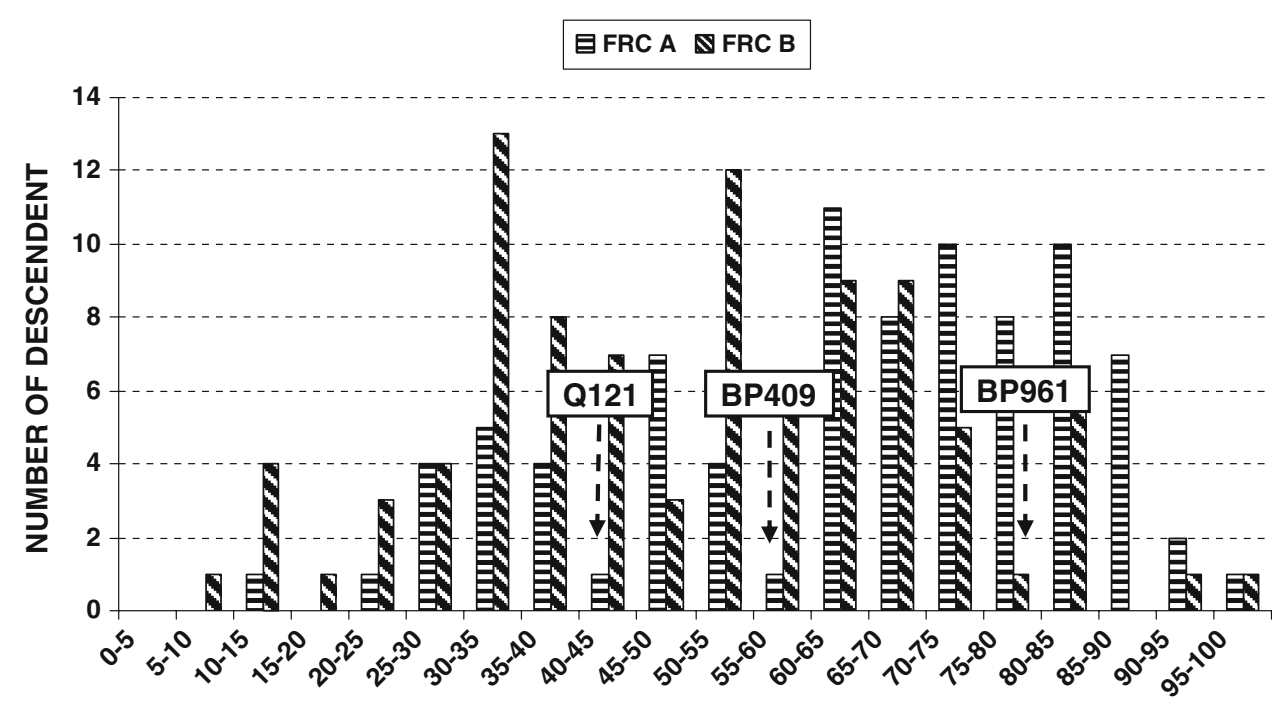

FREQUENCY OF ROOTED CUTTING 
Table 6 QTL determination for somatic embryogenesis and cutting ability of Coffea canephora Pierre

\begin{tabular}{llllrrrrr}
\hline Trait $^{\mathrm{a}}$ & $\begin{array}{l}\text { Number of } \\
\text { observed individual }\end{array}$ & Linkage group & LOD & \% Exp & K & $d f$ & Favorable parent \\
\hline FMC3 & 162 & $\mathrm{~A}$ & $\mathrm{~A}$ & 3.1 & 9 & 10.6 & 1 & Q121 \\
FMC6 & 162 & $\mathrm{G}$ & 3.2 & 9 & 11.3 & 1 & Q121 \\
FSE3 & 162 & $\mathrm{G}$ & 4.0 & 11 & 20.1 & 1 & Q121 \\
FSE6 & 162 & $\mathrm{G}$ & 3.9 & 11 & 16.0 & 1 & Q121 \\
ANERE3 & 162 & $\mathrm{G}$ & 2.7 & 7 & 9.9 & 1 & Q121 \\
ANERE6 & 162 & $\mathrm{G}$ & 3.5 & 10 & 14.7 & 1 & Q121 \\
ANEP3 & 162 & $\mathrm{G}$ & 3.2 & 9 & 21.2 & 1 & Q121 \\
ANEP6 & 162 & $\mathrm{~A}$ & 3.5 & 10 & 16.5 & 1 & Q121 \\
ALR & 75 & $\mathrm{G}$ & 4.5 & 27 & 18.0 & 3 & BP961 and Q121 \\
MLS & 164 & 3.7 & 12 & 13.7 & 1 & Q121 \\
\hline
\end{tabular}

a The abbreviations were showed in Tables 4 and 5

of QTLs with low effects. In order to test this hypothesis we merged the two CP populations in a single Q121 backcross segregating population (171 individuals) by using only markers heterozygous for Q121 and homozygous for the two BP clones. The results of this QTLs analysis for SE and cutting abilities are reported in Table 6 and on the consensus genetic map in the Fig. 5.

On this Back Cross Q121 population significant QTLs were detected for all criteria expressing SE ability: FSE3, FSE6, ANERE3, ANERE6 ANEP3, and ANEP6. It is interesting to note that these QTLs are all coming from the parent Q121 which has the lowest SE ability. In this regards these QTLs could be considered as transgressive.

The six QTLs for SE are co-localized in the upper part of the linkage group G. These QTLs (FSE, ANERE and ANEP) are detected at both observation times (3 and 6 months) which therefore indicate a quite stable expression. The variance explained for these QTLs is rather low ranging from 7 to $11 \%$ expressing a low genetic effect, which might be the reason for not detecting these QTLs in the two CP progenies.

The significant correlations among these traits ( $\mathrm{r}$ index ranging from 0.52 to 0.99 ) and the co-location of the six QTLs are suggesting the presence of one single QTL for these traits.

Two other QTLs, for micro callusing (FMC3 and FMC6) with LOD scores of 3.1 and 3.2, respectively, are co-localized on the linkage group (A). Each of these QTLs explains about $8 \%$ of the variance. The similarity of the LOD scores and the explained variance at 3 and 6 months let suppose that micro-calli frequency is, as SE ability, a stable response to in vitro culture

It must also be noticed that these two QTLs for microcallusing (FMC) from Q121 are consistent with the high micro callusing ability of this parent. On the contrary of what has been noticed for SE ability these QTLs could therefore not be considered as transgressive ones.
Two QTLs were identified for cutting ability: one for ALR in CPA progeny and one for MLS in Back Cross Q121 population.

These two QTLs for cutting ability are localized on two different linkage groups $A$ and $G$, respectively. They are in a different location from those observed for SE ability (Fig. 5). The QTL for ALR explained $27 \%$ of the variance observed. The second QTL (MLS) is explaining $12 \%$ of the trait variability.

\section{Discussion}

Somatic embryogenesis and cutting

Coffee SE looks largely influenced by the culture conditions, especially the medium composition, even if it varies a lot in intensity according to the genotype. Plant growth regulator is also critical for embryogenesis of coffee. The development of somatic embryos in absence of plant growth regulator has never been reported. The inductive effect of plant growth regulator (BAP and IAA) and lighting was reported in C. arabica (Gatica et al. 2008). The use of cytokinin as sole plant growth regulator to induce SE has been reported for C. canephora (Ducos et al. 2003b; Hatanaka et al. 1991; Yasuda et al. 1985). However, a combination of auxin and cytokinin has also been reported for $C$. arabica (Gatica-Arias et al. 2008). The nitrogen content is also known to be a key factor regulating the SE frequency in Coffea species (Samson et al. 2006).

The time needed to observe the first coffee somatic embryo varies from one to more than 12 months depending on the protocol (ex: gelling agent, lighting,...) (Ducos et al. 2007; Gatica et al. 2008; Giridhar et al. 2004; MenendezYuffa and de Garcia 1997; Pierson et al. 1983). For example, a combination of an agar solidified medium with 
Fig. 5 Genetic consensus map on two linkage groups showing the QTL locations for somatic embryogenesis and cutting abilities. (FMC3 and FMC6) Frequency of micro calli without somatic embryos at third and sixth months, (FSE3 and FSE6) frequency of somatic embryogenesis at third and sixth months, (ANEP3 and ANEP6) number of somatic embryo per Petri dish at third and sixth months, (ANERE3 and ANERE6) number of somatic embryo per reactive explant at third and sixth months, (ALR) average length of cutting root and maximum shoot length of cutting (MLS). The lines, at the right of the linkage groups, are estimating the location of the different QTLs with $\alpha=5 \%$. The underlined locus for each QTL shows the nearest locus associated with this trait. SGN-U identifier is link to the coffee unigenes that can be found on SOL web site (http://solgenomics.net/index.pl)
A

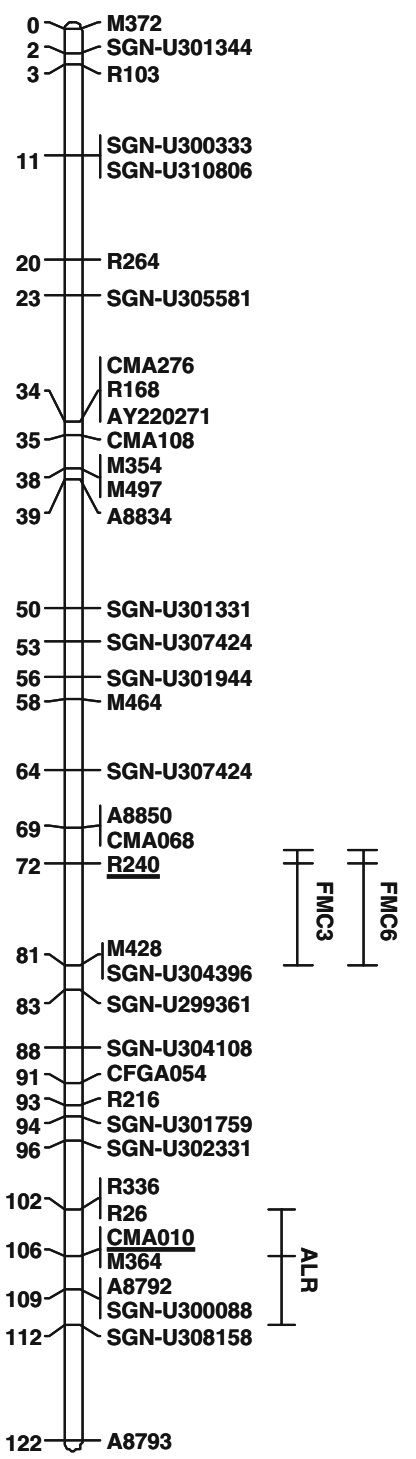

G

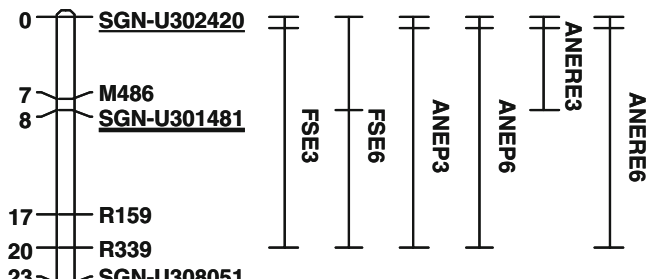

23] SGN-U308051
24 SGN-U311802

26 CMA098

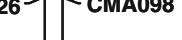

$36-$ M358

40 $\mathrm{M} 363$

42 $13307(B)$

43 R157

$46-$ M310

$55 \smile$ M499

56 CMA249

$59-$ SGN-U300438

$66 \sqrt[\text { SGN-U310293 }]{\text { SG }}$

- M387

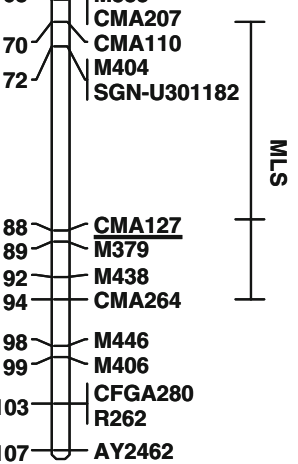

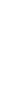

darkness (Ducos et al. 2003a) leads to a longer induction time than the combination of gelrite solidified medium with a 16-h photoperiod as used in this study. The short time needed to express SE is very specific of this study. It might be explained by a rapid and direct embryogenic polarization of some somatic cells without an intermediate phase of undifferentiated callus proliferation. As reported by Quiroz-Figueroa et al. (2002), the SE of coffee can also be shortened when using young leaves of seedlings pre-conditioned in vitro with auxin plus cytokinin.

Under the given experimental conditions of this study, the SE ability of genotypes belonging to two genetically diverse groups of $C$. canephora looks dependent on genotype. Large variation of SE intensity was observed within and among genetic groups of $C$. canephora. The dependence of SE ability to genotype has been already reported both in $C$. canephora (Michaux-Ferrière et al.
1989) and C. arabica (Molina et al. 2002). These results indicate that, under given conditions, the cellular totipotency, at the origin of SE formation is under control of genetics.

The highly significant correlation $(r=0.81)$ between the SE frequency and the number of embryos per embryogenic explant shows that the qualitative ability to induce first somatic embryos is correlated to further quantitative intensity of the phenomena. A model where SE is divided in two different steps was proposed by FloresBerios et al. 2000. The first step is a cell re-programming, conferring the ability to form embryos like for animal "stem cells". The second step is the formation of embryo from these re-programmed cells. In this research, the first step is expressed by the frequency of SE: how many explants have been re-programmed? The second step is expressed by the number of embryos produced per explant: 
How many embryos have been formed on this re-programmed explant?

The number of embryos obtained after 6 months of culture is significantly higher than after 3 months. This observation might result of two phenomena. First, as mentioned above, some proliferating cells continue to form embryos. Second, some embryo cells are at the origin of new embryos while increasing culture time. The occurrence of this secondary SE process could also contribute to increase the embryo number between 3 and 6 months of culture. Mature somatic embryos might therefore be ideal explants for the induction of secondary somatic embryos as shown on cassava (Mathews et al. 1993), peanut (Little et al. 2000), tea (Akula et al. 2000), cacao (Maximova et al. 2002), chestnut (Corredoira et al. 2003), grapevine (Pinto-Sintra 2007) and carnation (Karami et al. 2007). This approach could be applied for some elite clones of $C$. canephora where the induction and maintenance of embryogenic calli for large scale production is difficult.

Some reports have also shown that SE ability of C. arabica might depend on the season where the explants are collected on the mother plant (Molina et al. 2002). Loyola Vargas et al. (1999) have also shown that the physiological and morphological maturity of tissues can determine the coffee SE response. Furthermore, QuirozFigueroa et al. (2002) reported that the position of collected leaves on the plant is also very important, the first two pairs of leaves express a poor embryogenic potential compared to the mature leaves.

For cutting ability, single node cutting were not treated by plant growth regulator. The single nodes were "naturally" able to form sprouts and roots. It could therefore be assumed that this cutting technique might be used for genetic studies of $C$. canephora rooting and sprouting ability. As it has been also shown by S. Mawardi (personal communication) the ability for cutting propagation is significantly affected by genetic factor.

The significant differences among parental clones and their progenies for both SE and cutting abilities, as well as the observed heritability lead to conclude that embryogenesis and cutting abilities are genotype-dependent in these given experimental conditions. However, it is likely that other experimental conditions would lead to a different distribution and to conclude to a genotype $\times$ environment (in vitro culture) interaction. SE ability is therefore genotype dependent but probably not for the absence/presence of embryogenesis whatever the culture conditions. It is likely that this phenomenon is involving genes expressed for zygotic embryogenesis with a regulation of expression determined by culture conditions. Polygenic control of in vitro traits has also been reported in alfalfa (Reisch and Binghman 1980), tomato (Koornneef et al. 1987), cotton
(Gawel and Robacker 1990), and sunflower (Bolandi et al. 2000).

It is also interesting to note that based on the correlation analyses and QTL observations SE and cutting abilities of $C$. canephora look to be independent. This is not surprising since they are involving different regeneration systems: bipolar structures for SE, pre-existing dormant secondary buds for sprouting and, mono-polar meristems for rooting. As shown above, $\mathrm{SE}$ in C. canephora Pierre is depending on cytokinin while rooted cutting generally requires auxin.

\section{Quantitative trait loci}

With this protocol the observation of SE ability might have been limited to 3 months of culture since all the QTLs detected at 6 months are co-localized with those detected at 3 months. Flores-Berios et al. (2000) also showed a large number of QTLs for sunflower SE localized in one single region. Previously, Koornneef et al. (1993) demonstrated that shoot formation from various tissue culture systems, including established calli and protoplast culture, was controlled by a major gene in tomato. On the contrary, a polygenic effect has been reported for QTLs determining SE in winter rye (Bolibok et al. 2007), maize (Krakowsky et al. 2006), rice (Taguchi-Shiobara et al. 2006), wheat (Jia et al. 2007), and barley (Munoz-Amatrianin et al. 2008).

The QTLs determining the frequency of micro calli (without SE) were detected with Q121 as favorable parent. This result is consistent with the observation that Q121 shows the highest micro callus frequency. It can therefore be assumed that micro callusing process is at least controlled by one gene. In fact, this characteristic is also interesting for SE since SE will likely not be possible when observing only micro calli. This characteristic might therefore be assessed and traced by QTLs as a negative trait to be avoided when looking for SE during marker assisted selection.

QTLs determining the cutting ability were detected for MLS and ALR. They are localized on linkage group G for MLS and on linkage group A for ALR. It suggests that root and sprout formation are controlled by different genes even if occurring simultaneously. Similar results were reported on Eucalyptus for fresh weight of shoots and rooting intensity which are localized on different chromosomes (Grattapaglia et al. 1995). Moreover, Han et al. (1994) showed that in vitro formation of adventitious roots and shoots in hybrid poplar are controlled by a major single gene in a $\mathrm{F}_{2}$ family.

Molecular markers linked to QTLs of interest are valuable tools for predicting the genotype value for traits such as SE that are difficult and/or expensive to evaluate. These markers could be used in marker-assisted breeding 
programs, but also to contribute for reverse genetics by map based cloning of the genes of interest within the QTL regions (Huang et al. 2007).

In this study, SE and cutting abilities of $C$. canephora have been shown to be independent as it is confirmed by the presence of QTLs on different chromosomal regions. For the cutting ability, one chromosomal region is associated with root length and another one with shoot length. These results should contribute to further understanding and development of clonal propagation of C. canephora, which has been shown to be commercially applicable by Ducos et al. (2007).

\section{Conclusions}

Across the two studied progenies, $12 \%$ of the individuals did not express any embryogenesis while all of them were capable to produce cuttings. We were able to identify significant QTLs for SE and cutting abilities. They are not co-localized meaning these two propagation methods are under control of different genes. The SE and cutting genetic determinisms of $C$. canephora are therefore independent mechanisms. This observation may be important since the use of these propagation technologies could complement each other.

It would also be very interesting to check whether these identified QTLs would also be observed with the same population when using another SE protocol such as the one developed by Ducos et al. (2003a). That would allow assessing the importance of genotype $x$ in vitro interaction.

The determination of these QTLs could lead to the identification of genes and pathways involved in these vegetative propagation methods. Today, few data about the genetic pathways of SE are available on dicotyledonous species. However, recently in grapevine, Schellenbaum et al. (2008), identified two types of genes such as somatic embryogenesis receptor kinases (SERK) involved in the acquisition of embryogenic competence in plant cells and LEC (Leafy Cotyledon) encoding transcription factors. These two types of small gene families were also expressed in coffee (data no shown), in different grain or young leaf stages according to SGN database (Lin et al. 2005).

Although more exhaustive QTL determinism is required, especially in regards to the genetic diversity of C. canephora, a direct application of this work could lead to the transfer of embryogenic or cutting ability to elite genotypes that respond poorly to such vegetative multiplication.

Acknowledgments The authors thank to Indonesian Coffee and Cocoa Research Institute, and PT Nestle Indonesia for supporting this project. Some of the SSRs used in this study are kindly provided by external contacts such as coded CMA and $\mathrm{M}$ coming from Pr. Graziosi (Trieste University) and IRD \& CIRAD (Poncet et al. 2007), respectively.

Open Access This article is distributed under the terms of the Creative Commons Attribution Noncommercial License which permits any noncommercial use, distribution, and reproduction in any medium, provided the original author(s) and source are credited.

\section{References}

Akula A, Becker D, Bateson M (2000) High-yielding repetitive somatic embryogenesis from mature peanut recovery in selected tea clone 'TRI 2025', by temporary immersion. Plant Cell Rep 19:1140-1145

Bolandi AR, Branchard M, Alibert G, Gentzbittel L, Berville A, Sarrafi A (2000) Combining ability analysis of somatic embryogenesis from epicotyle layers in the sunflower (Helianthus annus L.). Theor Appl Genet 100:621-624

Bolibok H, Gruszcczynska A, Hromada-Judycka A, RakoczyTrojanowska M (2007) The identification of QTLs associated with the in vitro response of rye (Secale cereale L.). Cell Mol Biol Lett 12:523-535

Corredoira E, Ballester A, Vieitez AM (2003) Proliferation, maturation and germination of Castanea sativa Mill. Somatic embryos originated from leaf explants. Ann Bot 92:129-136

Davis AP, Goverts R, Bridson DM, Staffelen P (2006) An annotated taxonomic conspectus of genus Coffea (Rubiaceae). Bot J Linn Soc 152:465-512

de Feria M, Jimenez E, Barbon R, Capote A, Chavez M, Quiala E (2003) Effect of dissolved oxygen concentration on differentiation of somatic embryos of Coffea arabica cv Catimor 9722. Plant Cell Tissue Organ Culture 72:1-6

Ducos JP, Alenton R, Reano JF, Kanchanomai C, Deshayes A, Pétiard $\mathrm{V}$ (2003a) Agronomic performance of Coffea canephora P. Somatic embryos originated from leaf explants. Euphytica 215:215-223

Ducos JP, Alenton R, Reano JF, Kanchanomai C, Deshayes A, Pétiard V (2003b) Agronomic performance of Coffea canephora P. trees derived from large-scale somatic embryo production in liquid medium. Euphytica 131:215-223

Ducos JP, Lambot C, Pétiard V (2007) Bioreactor for coffee mass propagation by somatic embryogenesis. Int J Plant Dev Biol $1: 1-12$

Flores-Berios E, Sarrafi A, Fabre F, Alibert G, Gentzbittel L (2000) Genotypic variation and chromosomal location of QTLs for somatic embryogenesis revealed by epidermal layers culture of recombinant inbred lines in the sunflower (Helianthus annus L). Theor Appl Genet 101:1307-1312

Frewen BE, Chen THH, Howe GT, Davis J, Rohde A, Boerjan W, Bradshaw HD (2000) Quantitative loci and candidate gene mapping of bud set and bud flush in populus. Genetics 154:837845

Gamborg OL, Murashige T, Thorpe TA, Vasil IK (1976) Plant tissue culture media. In Vitro 72:473-478

Gatica AM, Arrieta G, Espinosa AM (2008) Direct somatic embryogenesis in Coffea arabica L cvs catura and catuai: effect of triacontanol, light condition, and medium consistence. Agronomia Costarricense 32(1):139-147

Gatica-Arias AM, Arrieta-Espinoza G, Esquirel AMS (2008) Plant regeneration via indirect somatic embryogenesis and optimisation of genetic transformation in Coffea Arabica 1 cvs catura and 
catuai. Electron J Biotechnol 11(1):1-15. doi:10.2225/vol11issue 1

Gawel NJ, Robacker CD (1990) Genetic control of somatic embryogenesis in cotton petiole callus culture. Euphytica 49:249-253

Giridhar P, Kumar V, Indu EP, Ravishankar GA, Chandrasekar A (2004) Thidiazuron induced somatic embryogenesis in Coffea arabica and C. canephora. Acta Bot Croat 63(1):25-33

Grattapaglia D, Bertolucci FL, Sederoff RR (1995) Genetic mapping of QTLs controlling vegetative propagation in Eucalyptus grandis and E. urophylla using a pseudo-testcross strategy and RAPD markers. Theor Appl Genet 90:933-947

Han KH, Bradshaw HD, Gordon MP (1994) Adventitious root and shoot regeneration in vitro is under major gene control in an $\mathrm{F}_{2}$ family of hybrid poplar (Populus trichocarpa $\times$ P. deltoids). Forest Genetic 1(3):139-146

Hatanaka T, Arakawa O, Yasuda T, Uchida N, Yamaguchi T (1991) Effect of plant growth regulators on somatic embryogenesis in leaf cultures of Coffea canephora. Plant Cell Rep 10:179-182

Holme IB, Torp AM, Hansen LN, Andersen SB (2004) Quantitative trait loci affecting plant regeneration from protoplast of Brassica oleracea. Theor Appl Genet 108:1513-1520

Huang XQ, Nabipour A, Gentzbittel Sarrafi A (2007) Somatic embryogenesis from thin epidermal layers in sunflower and chromosomal region controlling the response. Plant Sci 173:247-252

Jia H, Yi D, Xue S, Xiang Y, Zhang C, Zhang Z, Zhang L, Ma Z (2007) Mapping QTLs for tissue culture response of mature wheat embryos. Mol Cells 23(3):323-330

Karami O, Deljou A, Karami-Kordestani G (2007) Secondary somatic embryogenesis in carnation (Dianthus caryphyllus L). Plant Cell Tissue Organ Culture 92:273-280

Koornneef M, Hanhard C, Martinelli L (1987) A genetic analysis of cell culture traits in tomato. Theor Appl Genet 74:633-641

Koornneef M, Bade J, Hanhard C, Horsman K, Schel J, Soppe W, Zabel P (1993) Characterization and mapping of a gene controlling shoot regeneration in tomato. Plant J 3:131-141

Kosambi D (1944) The estimation of map distances from recombination values. Ann Eugen 12:172-175

Krakowsky MD, Lee M, Garay L, Woodman-Cikeman W, Long MJ, Sharopova N, Frame B, Wang K (2006) Quantitative trait loci for callus initiation and totipotency in maize (Zea mays L.). Theor Appl Genet 113:821-830

Lall S, Nettleton D, de Cook R, Che P, Howell SH (2004) Quantitative trait loci associated with adventitious shoot formation in tissue culture and the program of shoot development in Arabidopsis. Genetics 167:1883-1892

Lannes SD, Zimmer PD, de Oliveira et al (2004) In vitro regeneration of irrigated rice (Oryza sativa L.) anthers and detection of associated QTL. Ciencia Rural 34(5):1355-1362

Lee D (2009) Quantitative trait loci. http://www.croptechnology. unl.edu/lesson.cgi?lessonID=979259458

Lin C, Mueller LA, McCarthy J, Crouzillat D, Pétiard V, Tanksley SD (2005) Coffee and tomato share common gene repertoires as revealed by deep sequencing of seed and cherry transcripts. Theor Appl Genet 112(1):114-130

Little EL, Magbanua ZV, Parrot WA (2000) A protocol for repetitive somatic embryogenesis from mature peanut epicotyls. Plant Cell Rep 19:351-357

Loyola-Vargas VM, Fuentenes-Cerda CF, Monforte-Gonzalez M, Mendez-Zeel M, Rojas-Herrera R, Mijangos-Cortes J (1999) Coffee tissue culture as a new model for the study of somaclonal variation. ASIC 18:302-307

Mano Y, Komatsuda T (2002) Identification of QTLs controlling tissue-culture traits barley (Hordeum vulgare L.). Theor Appl Genet 105:708-715
Mathews H, Schopke C, Carcamo R, Chavarriaga P, Fauquet C, Beachy RN (1993) Improvement of somatic embryogenesis and plant recovery in cassava. Plant Cell Rep 12:328-333

Maximova SN, Alemanno L, Young A, Ferriere N, Traore A, Guiltinan MJ (2002) Efficiency, genotypic variability, and cellular origin of primary and secondary somatic embryogenesis of Theobroma cacao L. In Vitro Cell Dev Biol Plant 38:252-259

Menendez-Yuffa A, de Garcia EG (1997) Morphogenic events during indirect somatic embryogenesis in coffee Catimor. Protoplasma 199:208-214

Michaux-Ferrière N, Biyesse D, Alvard D, Dublin D (1989) Etude histologique de l'embryogenèse somatique chez Coffea arabica, induite par culture sur milieux uniques de fragments foliaires de génotypes déférents. Café Cacao Thé 33:207-217

Molina DM, Aponte ME, Cortina H, Moreno G (2002) The effect of genotype and explant age on somatic embryogenesis of coffee. Plant, Tissue and Organ Culture 71:117-123

Munoz-Amatrian M, Castillo AM, Chen XW, Cistué L, Vallés MP (2008) Identification and validation of QTLs for green plant percentage in barley (Hordeum vulgare L.). Mol Breed 22:119-129

Murashige T, Skoog F (1962) A revised medium for rapid growth and bioassay with tobacco tissue cultures. Physiol Plant 15(3):473497

Pétiard V, Lepage Brigitte, Lambot C, Crouzillat D, Florin B, Alvarez m, Von Rutte S, Leloup V, Gancel C, Labbe D, Liardon R (2004) Establishment evaluation of collections of Coffea arabica and Coffea canephora cultivated varieties. In: Association Scientifique International du Café (ASIC), eds. 20th international scientific colloquium on coffee, Bengalor

Pierson ES, van Lammeren AAM, Schel JHN, Staritsky G (1983) In vitro development of embryoid from punched leaf discs of Coffea canephora. Protoplasma 115:208-216

Pinto-Sintra AL (2007) Establishment of embryogenic cultures and plant regeneration in the Portuguese cultivar 'Touriga Nacional' of Vitis vinifera L. Plant Cell Tissue Organ Culture 88:253-265

Poncet V, Dufour M, Hamon P, Hamon S, de Kochko A, Leroy T (2007) Development of genomic microsatellite markers in Coffea canephora and their transferability to other coffee species. Genome 50:1156-1161

Priyono (2004) In vitro culture of coffee leaves for evaluating the capability of somatic embryogenesis of several coffee species. Pelita Perkebunan 20:110-122

Quiroz-Figueroa FR, Fuentes-Cerda CFJ, Rojas-Herrera R, LoyolaVargas VM (2002) Histological studies on the developmental stages and differentiation of two different somatic embryogenesis system of Coffea arabica. Plant Cell Tissue Organ Culture 20:1141-1149

Reisch B, Binghman ET (1980) The genetic control of bud formation from callus culture of diploid alfalfa. Plant Sci Lett 20:71-77

Samson N, Campa C, Gal L, Noirot M, Thomas G, Lokeswari T, de Kochko A (2006) Effect of primary culture medium composition on high frequency somatic embryogenesis in different Coffea species. Plant Cell Tiss Organ Cult 86:37-45

Schellenbaum P, Jacques A, Maillot P, Bertsch C, Mazet F, Farine S, Walter B (2008) Characterization of VvSERK1, VvSERK2, VvSERK3 and VvL1L genes and their expression during somatic embryogenesis of grapevine (Vitis vinifera L.). Plant Cell Rep 27:1799-1809

Schiantarelli E, De la Pena A, Candela M (2001) Use of recombinant Ingrid lines to identify, locate and map major genes and quantitative trait loci involved with in Vitro regeneration ability in Arabidopsis thaliana. Theor Appl Genet 102:335-341

Scotti-Saintagne C, Bertocchi E, Berreneche T, Kremer A, Plomion C (2005) Quantitative trait loci mapping for vegetative propagation in pedunculate oak. Ann For Sci 62:369-374 
Sondahl MR, Sharp W (1977) High frequency induction of somatic embryos in cultured leaf explants of Coffea arabica L. Z. Pflanzenphysiol 81:395-408

Staritsky G (1970) Embryoid formation in callus culture of coffee. Acta Bot Neerl 19:509-514

Taguchi-Shiobara F, Lin SY, Tanno K, Komatsuda T, Yano M, Sasaki T, Oka S (1997) Mapping quantitative trait loci associated with regeneration ability of seed callus in rice, Oryza sativa L. Theor Appl Genet 95:828-833

Taguchi-Shiobara F, Yamamoto T, Yano M, Oka S (2006) Mapping QTLs that control the performance of rice tissue culture and evaluation of derived near-isogenic lines. Theor Appl Genet 112:968-976

Uno A, Ohyama K, Kosai T, Kubota C (2003) Photoautotrophic culture with $\mathrm{CO}_{2}$ enrichment for improving micropropagation of
Coffea arabusta using somatic embryos. Acta Hortic 625:271277

Van Ooijen JW (2004) MapQTL ${ }^{\circledR} 5$ Software for the mapping of quantitative trait loci in experimental populations. Kyazma, Wageningen

Van Ooijen JW (2006) Joinmap ${ }^{\circledR} 4$ Software for the calculation of genetic linkage maps in experimental populations. Kyazma, Wageningen

Yasuda T, Fuji Y, Yamaguchi T (1985) Embryogenic callus induction from Coffea arabica leaf explants by benzyladenine. Plant Cell Physiol 26:595-597

Zamarripa A, Ducos JP, Tessereau H, Bollon H, Eskes AB, Petiard V (1991) Production of coffee somatic embryos in liquid medium: effect of inoculation density and renewal of the medium. Cafe Cocoa Thé 35:233-244 